\title{
Diary of Events
}

To have your meeting considered for listing below, please email details to ad_sales@cambridge.org

\section{DOHaD Society World Congresses}

2011, September:

$7^{\text {th }}$ World Congress on Developmental Origins of Health and Disease Marriott Portland Hotel, Downtown Waterfront, Portland, Oregon, USA. In partnership with Oregon Health Sciences University

18-21 September 2011

www.dohad2011.org

2013:

$8^{\text {th }}$ World Congress on Developmental Origins of Health and Disease Singapore

In partnership with the Singapore Institute of Clinical Sciences and the National University of Singapore

2013 (dates and venue to be announced)

\section{Other Meetings Associated With/Sponsored by the DOHaD Society}

\section{0, March:}

Perinatal Programming - The State of the Art

Charite Campus Mitte, Berlin, Germany

4-6 March 2010

www.perinatal-programming-2010.de

\section{0, May:}

The Power of Programming

Großhadern Campus, University Hospital, Munich, Germany

Abstract deadline 15th February 2010

Earlybird registration deadline 28th February 2010

6-8 May 2010

www.metabolic-programming.org/munich2010/

\section{0, June:}

International Workshop on Developmental Origins of Health and Disease Beijing, China

Official language English
27 June 2010

Further details available by Email zhanglidr@gmail.com

2010, July:

Fetal and Neonatal Physiological Society

King Alfred's College, Winchester, UK

Abstract and registration deadline: 26th March 2010

4-7 July 2010

www.fnps-society.org

\section{Other Important Meetings}

\section{0, March:}

57th Annual Scientific Meeting of The Society for Gynecologic Investigation (SGI)

Orlando, Florida, USA

24-27 March 2010

www.sgionline.org

\section{0, April:}

Developmental Origins and Epigenesis in Health and Disease Swissotel The Stamford, Singapore

26-30 April 2010

www.keystonesymposia.org

2010, May:

22nd European Congress on Perinatal Medicine

Granada Conference and Exhibition Centre, Granada, Spain 26-29 May 2010

www.ecpm2010.org/eng

\section{0, August:}

2010 Aspen Perinatal Biology Conference

Intrauterine Stress and Adverse Fetal Outcomes - Linked by Perinatal Mechanisms of Adaptation

The Given Institute, Aspen, Colorado, USA

28-31 August 2010

Contact Information: 1thompson1@umm.edu 